\title{
The Important Role of Metal Ions for Survival of Francisella in Water within Amoeba Environment
}

\author{
Mateja Ozanic $\left(\mathbb{D},{ }^{1}\right.$ Valentina Marecic ${ }^{(D)},{ }^{1}$ Masa Knezevic $\left(\mathbb{D},{ }^{1}\right.$ Andrea Majstorovic ${ }^{(D)}{ }^{2}$ \\ Paula Zurga ${ }^{D},{ }^{3}$ Marija Curlin $\left(\mathbb{D},{ }^{4}\right.$ Vanda Piskur $\left(\mathbb{D},{ }^{3}\right.$ Danijela Lenac ${ }^{(D)}{ }^{5}$ \\ Aleksandar Bulog $\mathbb{D}^{3}$ and Marina Santic $\mathbb{D}^{1}$ \\ ${ }^{1}$ Department of Microbiology and Parasitology, Faculty of Medicine, University of Rijeka, Rijeka, Croatia \\ ${ }^{2}$ Department of Biotechnology, University of Rijeka, Rijeka, Croatia \\ ${ }^{3}$ Teaching Institute of Public Health of Primorje-Gorski Kotar County, Rijeka, Croatia \\ ${ }^{4}$ Department of Histology and Embryology, Faculty of Medicine, University of Zagreb, Zagreb, Croatia \\ ${ }^{5}$ Water Supply Company-KD Vodovod i, Kanalizacija, Rijeka, Croatia
}

Correspondence should be addressed to Marina Santic; marina.santic@medri.uniri.hr

Received 28 December 2020; Revised 22 March 2021; Accepted 27 March 2021; Published 12 April 2021

Academic Editor: Maria Bayliak

Copyright (C) 2021 Mateja Ozanic et al. This is an open access article distributed under the Creative Commons Attribution License, which permits unrestricted use, distribution, and reproduction in any medium, provided the original work is properly cited.

Francisella tularensis is a gram-negative facultative intracellular bacterium that resists harsh environments. Several outbreaks of tularemia are linked to the consumption and contact with spring water. The number of $F$. tularensis in some waters is high, while in others, this bacterium does not survive. Except organic compounds, metals could be important for the survival of $F$. tularensis in water. Some Francisella strains showed the association with amoeba, which may act as the environmental reservoir. This study was aimed at following the role of metal ions and/or amoeba in the existence and replication of F. novicida in spring waters by growth kinetics, acquisition of metals, and ultrastructural analyses of bacteria. The bacteria showed a longer survival in water with higher initial concentrations of $\mathrm{Mn}$ and $\mathrm{Zn}$. Although $\mathrm{Mn}$ and $\mathrm{Zn}$ were necessary for the survival of $F$. novicida, the results also showed that the bacterium does not grow in water with high levels of $\mathrm{Zn}$. In contrast, high levels of Mn did not have such a negative effect on the survival of this bacterium in water. In addition, while $F$. novicida benefits presence of amoeba in spring water, the number of amoebae is decreasing in a coculture model with F. novicida.

\section{Introduction}

Francisella tularensis is a highly infectious gram-negative bacterium and a causative agent of the disease tularemia in humans and animals. The genus Francisella contains five species: F. tularensis, F. philomiragia, F. hispaniensis, F. noatunensis, and F. novicida [1]. Two subspecies of F. tularensis, tularensis (type A) and holarctica (type B), cause most of the illness in humans. While $F$. novicida is avirulent in immunocompetent humans, it is highly virulent in experimental mice [1]. A new species of Francisella related to the water environment has been discovered using a PCR-based identification [2]. F. salina and F. uligins have been isolated from seawater, while F. guangzhouensis and F. frigiditurris were found within cooling towers [2]. F. adeliensis survives within ciliate Euplotes petzi [3].

Tularemia is a bacterial zoonotic disease, widespread in the northern hemisphere, and mostly occurring in forest and mountain regions where it affects a wide range of mammals [4]. More than 300 wild and domestic animal species worldwide have been infected with $F$. tularensis [5]. Human infections usually occur by direct contact with animals, insect bites, and ingestion of contaminated food and water or through various aquatic activities such as swimming or fishing [6]. Reservoirs of bacteria vary depending on climate, geographical region, and the presence of animals. While in Scandinavia, the bacterium is spread by mosquitoes, in Southern Europe, environmental water is an essential niche 
in the transmission of the disease to humans [2]. A number of recent studies suggested a long-term survival of $F$. tularensis in different natural aquatic environments, such as natural spring waters, brackish waters, and salt waters [2, 7].

Free-living amoebae, including Acanthamoebae castellanii, Dictyostelium discoideum, Hartmannella vermiformis, and Naegleria gruberi, are ubiquitous organisms within soil and water environments [8]. In the natural waters, they are considered not only a contaminant but also a source of microorganisms pathogenic for humans $[8,9]$. It has been shown that within the intracellular milieu of amoebae, pathogens are protected from environmental conditions and disinfectants, making their survival and dissemination more effective [9]. These pathogens are resistant to phagocytosis by amoebae and survive within protozoa by different mechanisms, including Mycobacterium spp., Coxiella burnetii, Francisella tularensis, Legionella pneumophila, Listeria monocytogenes, Helicobacter pylori, and Yersinia pestis [9].

Previous studies have shown that Francisella species are able to penetrate and multiply within $H$. vermiformis, $A$. castellanii, and Dictyostelium discoideum [10-12]. Within $H$. vermiformis trophozoites, F. novicida is localized and replicated within vacuoles [12]. Survival of Francisella within amoebal cysts for several weeks could be of great importance for a long-term persistence of Francisella spp. within the water environment and transmission to other reservoirs in the nature [13]. The fine-tuning between bacteria and protozoa is needed to be able to resist harsh environmental conditions in water.

It is interesting that some spring waters in the southern part of Europe are more often contaminated with F. tularensis, whereas from other waters, the bacterium has never been isolated. In the last two decades, tularemia cases connected with drinking water have been reported in Kosovo, Turkey, Bulgaria, Macedonia, Georgia, Italy, Germany, Norway, and Sweden $[2,13]$. Probably, the greatest part in the existence of Francisella in certain waters is related to the environmental features, as well as the biochemical characteristics of the water.

The ability of bacteria to survive and replicate in specific environmental conditions depends also on their capacity to adapt to some limited nutrition factors in their surroundings. The high abundance of nutrients together with the presence of nanoflagellates favors the survival of $F$. tularensis subsp. holarctica in lake waters [14]. It has also been shown that $F$. tularensis subsp. holarctica enters a viable but nonculturable (VBNC) state after 5 days in coculture with protozoa. Interestingly, the bacterium loses its virulence over time, being present in these waters regardless of nutrients and ciliate presence [14], and does not manifest virulence in mice in a VBNC state [15].

As with other pathogens, $F$. tularensis utilizes different nutrients, such as transition metals, from its host. Transition metals, such as iron, zinc, and manganese, have proved to be essential for bacterial survival and replication due to their role as structural components of enzymes, storage proteins, and transcription factors $[16,17]$. Metal ions are indispensable to bacteria not only for metabolic processes but also for its virulence [17]. It has also been shown that F. tularensis subsp. tularensis type A survives much better in brackish water than in freshwater [7]. Previous research demonstrated that the salinity of brackish water increases the mobility and overall concentration of metals such as $\mathrm{Cd}, \mathrm{Cu}$, and $\mathrm{Ni}$ [18].

The $\Delta f_{s} l E$ mutant of $F$. tularensis LVS, defective in iron acquisition systems, is unable to grow within macrophages and is attenuated in virulence, suggesting that the acquisition of this metal plays a crucial role in intracellular growth [19]. Availability of zinc has been shown to be necessary for the survival of different bacteria; however, the excess of zinc can also have a toxic influence [20]. Maintaining zinc homeostasis is especially important for intracellular pathogens, including the genus Francisella, since host cells have multiple mechanisms for controlling free zinc levels intracellularly [20]. Furthermore, manganese also plays a significant role in the adaptation of pathogenic bacteria to the human host [21]. Pathogens utilize manganese as a key nutrient to resist the effects of host-mediated oxidative stress; hence, the deletion of manganese import systems compromises the virulence and viability of some bacteria [21].

In this study, factors contributing to $F$. novicida survival within the water samples were investigated by using organic (amoeba) and inorganic sources (metal ions). The water samples were chosen based on different concentrations of metal ions. Water sample 1 was collected from the largest permanent karst spring in Croatia, with high initial concentrations of Mn. Water sample 2, with low concentration of Mn, was collected from the artificial lake, which is the main groundwater source on the island in Croatia. However, the initial concentrations of $\mathrm{Zn}$ ions were similar in both water samples.

The results of this study showed that the survival of Francisella in water environment depends on the concentration of amoebae and metal ions. The lower or higher concentrations could be the dead end for Francisella in the water environment.

\section{Materials and Methods}

2.1. Bacterial Strain, Amoebal Strain, and Water Samples. F. novicida U112 was obtained from Anders Sjöstedt (University of Umeå, Sweden) and was grown on Buffered Charcoal-Yeast Extract (BCYE) agar at $37^{\circ} \mathrm{C}$ and $5 \% \mathrm{CO}_{2}$ atmosphere for 48 hours.

A. castellanii was obtained from the American Type Culture Collection, 30234. The amoebae were grown in a medium 30234 at $25^{\circ} \mathrm{C}$.

Water sample 1 was collected from one of the largest permanent karst springs in Croatia, Zvir II. Its discharge capacity varies between 0.9 and $7.5 \mathrm{~m}^{3} / \mathrm{s}$ and is supplying Rijeka's residents with water. Water sample 2 was collected from the Ponikve artificial lake, which is the main groundwater source on the island of Krk, the largest island in Croatia.

2.2. Growth Kinetics of F. novicida in Water Samples. To determine the growth kinetics of $F$. novicida in spring water, bacteria were added to the water samples at a concentration of $10^{7} \mathrm{CFU} / \mathrm{ml}$ and incubated for 10 days at room temperature. After 1, 3, 5, 8, and 10 days, the bacterial number in water was determined by plating the serial dilutions on BCYE 
agar. Experiments were performed in triplicate and repeated three times.

2.3. Influence of Different Concentrations of Manganese and Zinc on the Growth Kinetics of F. novicida in Water. For testing the influence of different transition metals on the growth kinetics of $F$. novicida, zinc $\left(\mathrm{ZnSO}_{4} \times 6 \mathrm{H}_{2} \mathrm{O}\right)$ and manganese $\left(\mathrm{MgCl}_{2} \times 4 \mathrm{H}_{2} \mathrm{O}\right)$ ions were added in ultrapure water at different concentrations $(0.1 \mu \mathrm{M}, 0.8 \mu \mathrm{M}, 0.1 \mathrm{mM}, 0.5 \mathrm{mM}$, and $1.0 \mathrm{mM}$ ), followed by inoculation of the bacteria at a concentration of $10^{7} \mathrm{CFU} / \mathrm{ml}$. The experiments were done at room temperature. At days 1, 2, 3, 4, and 5 after the inoculation of bacteria, the $\mathrm{CFU} /$ milliliter of $F$. novicida was determined by plating the serial dilutions on BCYE agar at $37^{\circ} \mathrm{C}$. Within this experiment, we used ultrapure sterile water due to the minimal concentration of transition metals. The growth kinetics of bacteria in ultrapure water without metal ions was considered as control. Experiments were performed in triplicate and repeated three times.

2.4. Coculture of F. novicida and A. castellanii in Water Samples. F. novicida and A. castellanii were coinoculated with water samples and incubated at room temperature for 30 days. Bacteria and amoeba were added to water samples at a concentration of $10^{7} \mathrm{~F}$. novicida/ml in a coculture with $10^{6} \mathrm{~A}$. castellanii/ml. Water samples with addition of $10^{7} \mathrm{~F}$. novicida/ml without amoebae, and $10^{6} \mathrm{~A}$. castellanii/ml without bacteria were used as a control. Growth kinetics of bacteria and amoeba were followed every five days for a period of 30 days. The number of $F$. novicida at each time point was determined by plating serial dilutions on BCYE agar plates as described in the previous section.

In order to determine the number of amoeba cells, at each time point, $1 \mathrm{ml}$ of water sample was transferred to a 24 -well plate and left for $2 \mathrm{~h}$ at room temperature to allow amoeba to adhere. It was followed by analysing the samples using light microscopy. Amoeba cells were counted, and representative images were taken by an Olympus microscope to study the morphology of the cells. All experiments were performed in triplicate and repeated three times.

2.5. Bacterial Morphology Observation by TEM. Transmission electron microscopy (TEM) analysis was performed to evaluate the morphology and structure of bacteria during the incubation period within water samples. Bacteria were prepared for TEM by negative staining. Bacterial suspension was applied to the carbon-coated 200-mesh copper grid for 2 min and drowned off from the edge of the grid with filter paper. After that, the grid was stained using $10 \mu \mathrm{l}$ of $2 \%$ phosphotungstic acid for $1 \mathrm{~min}$ and again drained on the filter paper. The grid was placed directly into the grid box and allowed to air-dry before observation. By electron microscopy (Jeol Electron Microscope JEM1011, Japan), we observed the morphology of the bacteria, including their size, shape, and density. Ten fields for each sample were randomly photographed. Experiments were performed in triplicate and repeated three times.

2.6. Determination of Manganese and Zinc Concentrations in Water Samples. Before inoculation of the bacteria and/or amoeba, the initial concentrations of transition metals $\mathrm{Zn}$ and $\mathrm{Mn}$ were determined in all water samples using an atomic spectrometer (AAS Perkin Elmer Analyst 200, SAD 2003). After the observed period of incubation, the samples were autoclaved. The bacteria were further removed by filtration, and the soluble concentration of remaining metal ions was determined again by an atomic spectrometer. Analyses were performed according to the standards accepted by the Croatian Standards Institute (HRN ISO standards), HRN ISO 15586:2008 for iron and manganese, and HRN ISO 8288:1998 for zinc. Experiments were performed in triplicate and repeated three times.

2.7. Statistics. Statistical analyses were performed using Statistica (StatSoft) software version 12 or with GraphPad Prism version 6.0 software. In all cases, the Student $t$-test $p<0.05$ was accepted as significantly different from the control sample and was denoted by $*$ in comparison to the control.

\section{Results and Discussion}

3.1. Important Role of $\mathrm{Mn}$ in the Survival of F. novicida in Water. While in Sweden and Finland tularemia is mainly transmitted by mosquito bites, human tularemia in Turkey, Kosovo, Bulgaria, and Macedonia is strongly connected to drinking water [2]. Knowledge of Francisella persistence within the aquatic environments is limited, largely because it is difficult to study bacteria in their natural environments. However, it is important to elucidate the mechanisms of long-term survival of this bacterium in natural ecosystems. Recent studies showed that seroprevalence in the human population is positively correlated with living near the coastline, including salt waters, brackish waters, and natural spring waters; however, the mechanisms of long-term survival of this bacterium in the water environment have still not been elucidated [2]. The temperature influences the survival of Francisella in water; however, the presence of different metal ions seems to be of critical importance for bacterial pathogenesis [20]. Studies by Berrada and Telford showed that the salinity of brackish water may be an important factor for the stability of $F$. tularensis subsp. tularensis in a water environment for a longer period in a cultivable form [7]. Brackish high-nutrient conditions, such as sulfurcontaining compounds, and the presence of protozoa favor the survival of F. tularensis subsp. holarctica in lake water [14].

Transition metals are involved in a wide range of crucial biological processes and therefore are essential for the survival of microorganisms [22]. Defects in the bacterium's ability to utilize metal ions and using it for its metabolism usually lead to avirulence $[16,22]$. However, the excess of metal ions can have a toxic effect on bacteria; hence, it is important for pathogens to ensure that the metal uptake and availability are in balance with the physiological needs $[16,23]$. Upon phagocytosis, phagocytes limit intravacuolar bacterial growth either by restriction of essential metal ions or by accumulating some metals to intoxicating concentrations [17]. However, some bacteria have developed special strategies to survive the excess of metal ions in the environment as well as inside the phagocytic cells [17, 24]. Microbial 
pathogens typically possess several tightly regulated metal transporters for the acquisition of metal ions such as iron, zinc, manganese, and copper, allowing them to adapt to changing environment conditions [25-27].

This study was aimed at determining if natural waters could serve as a medium for long-term survival of Francisella in the environment and the role of certain metal ions in this process.

To determine if the growth kinetics of $F$. novicida in natural spring waters depends upon transition metals such as $\mathrm{Mn}$ and $\mathrm{Zn}$, we used two spring water samples, which highly differ from each other regarding the initial concentrations of metal ions, water sample 1 with high initial concentration of these metal ions and water sample 2 with low concentration of metals, especially manganese. The bacterium was inoculated in water samples at the concentration of $10^{7} \mathrm{CFU} / \mathrm{ml}$. At $1,3,5,8$, and 10 days after the inoculation of bacteria, water samples were plated on BCYE agar to determine the number of $F$. novicida. To determine which metal ions bacteria utilize for survival and growth, we measured the concentrations of $\mathrm{Mn}$ and $\mathrm{Zn}$ ions in both water samples before and 10 days after the inoculation of bacteria.

In water sample 1 , where the initial levels of $\mathrm{Mn}$ ions were significantly higher, the number of bacteria was slightly decreased during 10 days of incubation; however, at day 10 , we still detected $10^{6}$ bacteria per $\mathrm{ml}$. The initial concentration of $\mathrm{Mn}$ ions in water sample 1 was $0.6 \mu \mathrm{M}$ and decreased to $0.036 \mu \mathrm{M}$ (Figure 1(a)) (Student $t$-test, $p<0.05$ ), while the concentration of $\mathrm{Zn}$ ions in this water sample was $0.550 \mu \mathrm{M}$ and decreased to $0.199 \mu \mathrm{M}$ after the observation period (Student $t$-test, $p<0.05$ ) (Figure 2(b)). We can conclude that during the observation period, the bacteria utilized high levels of $\mathrm{Mn}$ and $\mathrm{Zn}$.

In contrast, $F$. novicida showed much lower ability to survive in water sample 2, where the initial concentrations of $\mathrm{Mn}$ were extremely low. In this water sample, the initial concentration of Mn ions was $<0.00546 \mu \mathrm{M}$ and did not change during the observation time (Figure 2(b)) (Student $t$-test, $p>0.05$ ), while the initial concentration of $\mathrm{Zn}$ ions in this water sample was $0.550 \mu \mathrm{M}$ and decreased to $0.077 \mu \mathrm{M}$ after growth of bacteria (Student $t$-test, $p<0.05$ ) (Figure 2(b)).

The initial concentration of $\mathrm{Zn}$ ions was similar in both water samples, and bacteria utilized this metal during the 10 -day incubation. We could speculate that while $\mathrm{Mn}$ is required for bacterial survival in water, the presence of $\mathrm{Zn}$ is not sufficient for it.

3.2. The Fine-Tuning of Manganese and Zinc Ions Results in the Survival of F. novicida in Water. The ability of Francisella to scavenge nutrients from the environment has proved to be essential for bacterial survival and replication in nature as well as in their host cells. Metal ions are required in many biological processes. However, it is well known that some transition metals, such as zinc, copper, silver, gold, and cadmium, can be used as antimicrobial agents, depending on their concentration [28]. To determine the precise concentrations of metal ions for promoting $F$. novicida growth, in vitro studies were done. The $\mathrm{Mn}$ and $\mathrm{Zn}$ ions were added into ultrapure sterile water at the concentrations of $0.1 \mu \mathrm{M}$,
$0.8 \mu \mathrm{M}, 0.1 \mathrm{mM}, 0.5 \mathrm{mM}$, and $1.0 \mathrm{mM}$, which were above or below their normal concentrations in water. It was followed by inoculation of bacteria at a concentration of $10^{7} \mathrm{CFU} / \mathrm{ml}$. Ultrapure water without metal ions was used as a control.

Surprisingly, the increased or decreased concentrations of $\mathrm{Mn}$ ions in water samples did not result in a significant change of F. novicida growth in the water. There was no statistical difference in the growth kinetics of $F$. novicida within water samples containing different concentrations of $\mathrm{Mn}$ ions (Student $t$-test, $p>0.05$ ) (Figure 1(a)). Within all water samples, the bacterial count was slowly decreasing from an initial concentration of $10^{7} \mathrm{CFU} / \mathrm{ml}$ to approximately $10^{5} \mathrm{CFU} / \mathrm{ml}$ during the 5 days of observation (Student $t$-test, $p>0.05$ ) (Figure 1(a)). This indicates that Francisella can tolerate a wide range of manganese ions to survive and replicate.

In contrast, we observed that the growth kinetics of $F$. novicida in water is dependent on $\mathrm{Zn}$ concentration. Bacteria showed the best growth in the water samples with the addition of $\mathrm{Zn}$ ions in a concentration of $0.1 \mu \mathrm{M}$ and $0.8 \mu \mathrm{M}$ (Student $t$-test, $p>0.05$ ) (Figure 1(b)). In those water samples, bacterial counts declined just for $1 \log$ during 5 days of experiment. In the water samples with $0.1 \mathrm{mM}$ concentration of $\mathrm{Zn}$, bacteria showed similar growth kinetics; however, during the 5 days, the bacterial count declined from the initial $10^{7} \mathrm{CFU} / \mathrm{ml}$ to $10^{4} \mathrm{CFU} / \mathrm{ml}$ (Student $t$-test, $p>0.05$ ) (Figure 1(b)). Interestingly, the concentration of $0.5 \mathrm{mM}$ and $1 \mathrm{mM}$ of $\mathrm{Zn}$ ions inhibited the growth of $F$. novicida and after 4 days, we could not cultivate $F$. novicida on agar (Student $t$-test, $p<0.05$ ) (Figure 1(b)).

These findings suggest that for metabolic function, Francisella needs exact concentration of $\mathrm{Zn}$ ions, while it is more tolerant for $\mathrm{Mn}$ ions in the environment. The misbalance of the concentration of $\mathrm{Zn}$ and $\mathrm{Mn}$ in water could trigger the bacteria to induce the VBNC state. In addition, our results also showed that in high levels of $\mathrm{Zn}$ in the water, bacteria did not grow on the agar plate. It is possible that the bacterium enters the VBNC state but it is still to be determined if the resuscitation from the VBNC state could be achieved by changing the concentration of $\mathrm{Zn}$ ions. In contrast, high levels of Mn did not have such a negative effect on the survival of this bacterium, showing that $F$. novicida possesses mechanisms of adaptation to the microenvironment with excess of this transition metal. Based on the results from water sample 1, it could be concluded that manganese is necessary to support the growth of this unique bacterium.

3.3. Francisella Benefits from Coculture with A. castellanii within Water Samples. It has been suggested that amoebal passage is a prerequisite for the development of some bacterial virulence factors including adaptation to life in the eukaryotic hosts $[29,30]$. Mechanisms allowing bacteria to escape from phagocytosis by amoebae are believed to be similar to the mechanisms used by bacteria to evade a similar fate by macrophages [31]. This is not the case for F. novicida. In amoeba, the bacterium is replicating in the vacuole, while in mammalian cells, Francisella is replicating in the cytosol. It has been shown that intracellular growth in A. castellanii enhances intracellular replication of L. pneumophila within 


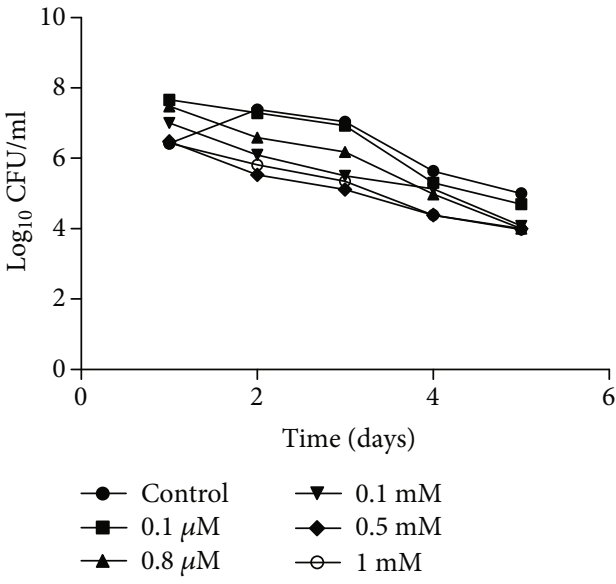

(a)

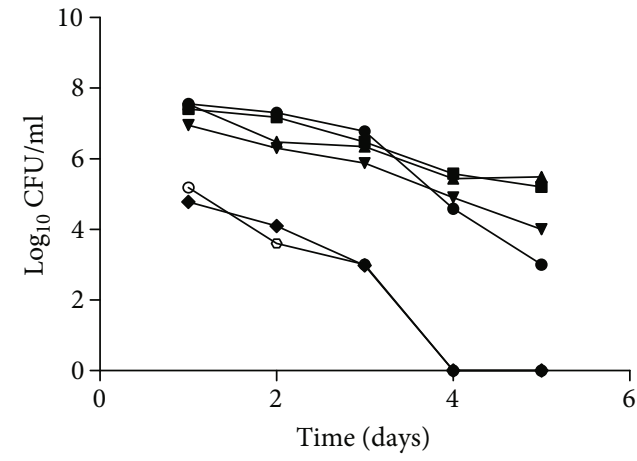

(b)

FIGURE 1: Influence of different concentrations of manganese and zinc on the growth kinetics of $F$. novicida in water samples 1 (a) and 2 (b). Zinc and manganese ions were added in ultrapure water at different concentrations $(0.1 \mu \mathrm{M}, 0.8 \mu \mathrm{M}, 0.1 \mathrm{mM}, 0.5 \mathrm{mM}$, and $1.0 \mathrm{mM})$, followed by inoculation of the bacteria at concentration of $10^{7} \mathrm{CFU} / \mathrm{ml}$. The experiments were performed at room temperature. At days $1,2,3,4$, and 5 , after the inoculation of the bacteria, the $\mathrm{CFU} /$ milliliter of $\mathrm{F}$. novicida was determined by plating the serial dilutions on $\mathrm{BCYE}$ agar at $37^{\circ} \mathrm{C}$. The growth kinetics of bacteria in ultrapure water without metal ions was considered as control. Experiments were performed in triplicate and repeated three times. Student $t$-test, ${ }^{*} p<0.05$ was accepted as significantly different from the control sample.

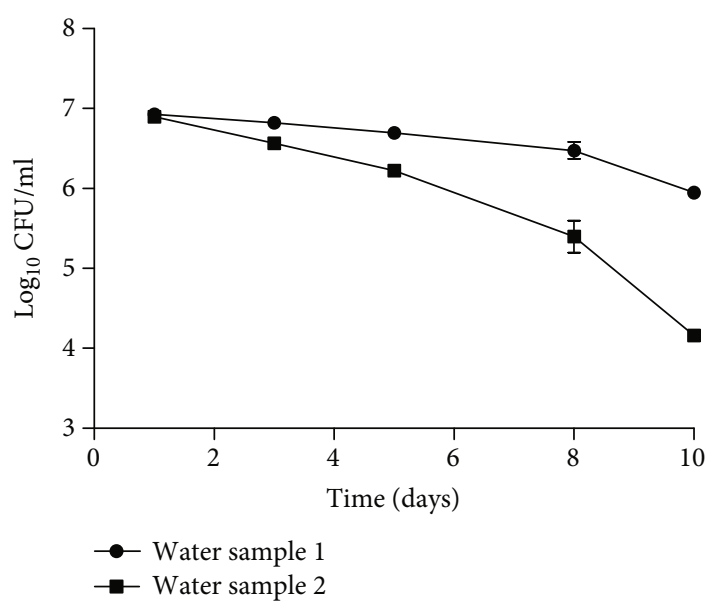

(a)

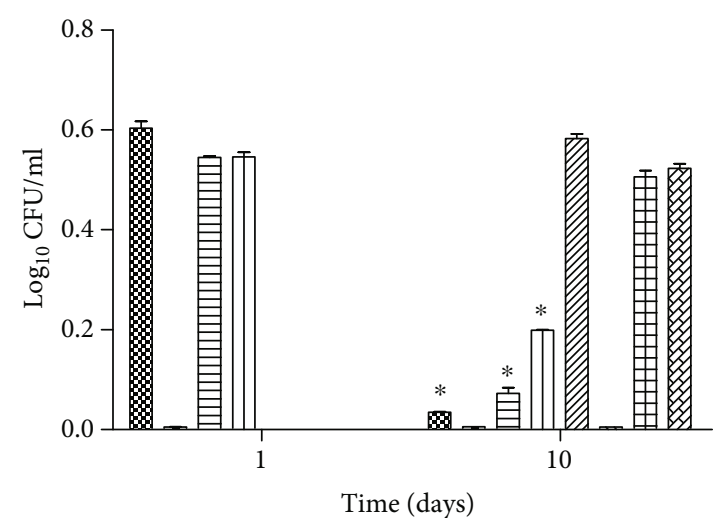

\begin{tabular}{|c|c|c|c|}
\hline 88 & Mn ws 1 & ZIII & Mn ws 1 control \\
\hline 표 & Mn ws 2 & & Mn ws 2 control \\
\hline & Zn ws 1 & & Zn ws 1 contr \\
\hline & Zn ws 2 & & Zn ws 2 control \\
\hline
\end{tabular}

(b)

FIGURE 2: Growth kinetics of F. novicida in water samples 1 and 2 (a) and the concentrations of manganese and zinc in the water samples during a 10 days of incubation (b). (a) To determine the growth kinetics of $F$. novicida, bacteria were added to the water samples at a concentration of $10^{7} \mathrm{CFU} / \mathrm{ml}$. After $1,3,5,8$, and 10 days, the bacterial number in water was determined by plating the serial dilutions on BCYE agar. (b) Before inoculation of the bacteria, the initial concentrations of transition metals $\mathrm{Zn}$ and $\mathrm{Mn}$ were determined in water samples using an atomic spectrometer (AAS Perkin Elmer Analyst 200, SAD 2003). After 10 days of incubation, the samples were autoclaved, the bacteria were removed by filtration, and the soluble concentrations of remaining metal ions were determined again by an atomic spectrometer. Experiments were performed in triplicate and repeated three times. Student $t$-test, ${ }^{*} p<0.05$ was accepted as significantly different from control samples without addition of bacteria.

monocytes and increases virulence in mice [32]. Interestingly, our group and the others showed that after growing in amoeba or being in the VBNC state, Francisella loses its virulence $[14,33]$. It could be that other factors are important for its fitness, for example, the availability of nutrients in the surroundings such as different metal ions.
To further investigate the influence of amoebae and/or metal ions in supporting the survival of F. novicida in water, additional studies were performed. Within the coculture experiment, the numbers of bacteria and amoebae were determined every 5 days, during 30 days of experiment. As a control, water samples without bacteria or amoeba were 


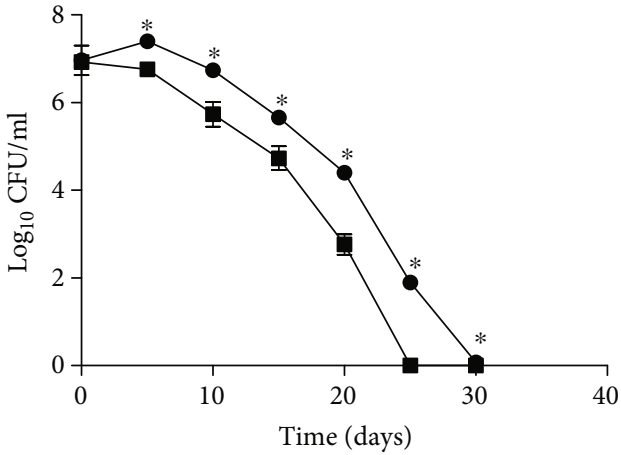

(a)

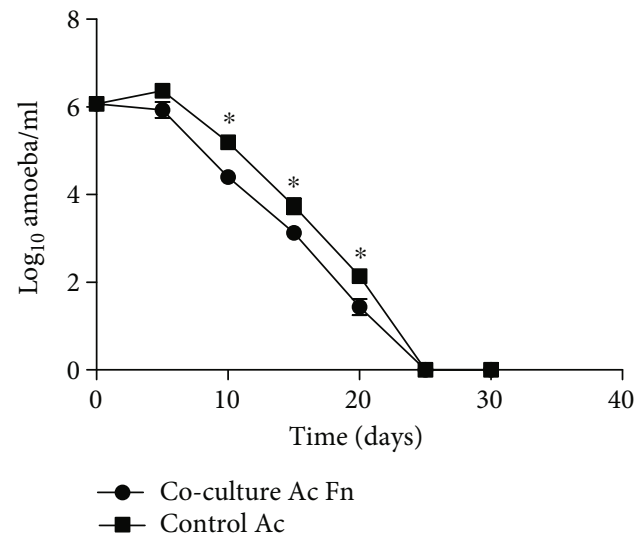

(c)

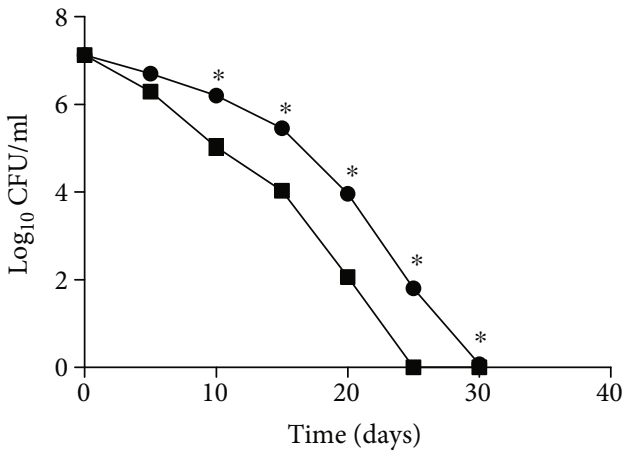

(b)

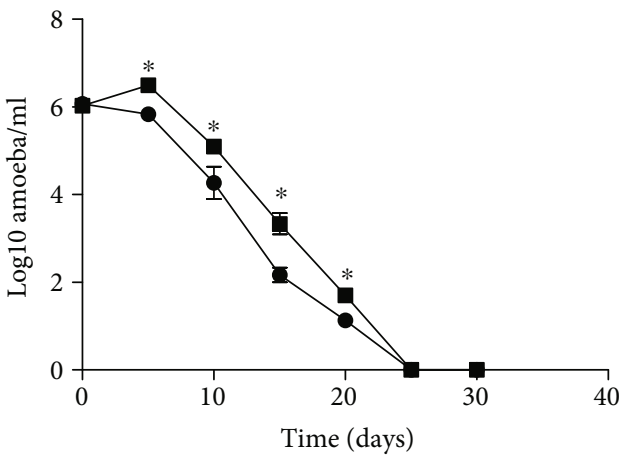

(d)

Figure 3: The growth kinetics of F. novicida in water samples 1 (a) and 2 (b) as well as A. castellanii in water samples 1 (c) and 2 (d) during a coincubation. F. novicida and A. castellanii were coincubated in water samples at room temperature for 30 days. Growth kinetics of bacteria and amoeba were followed every five days in a period of 30 days. Water samples with addition of $F$. novicida without amoebae and $A$. castellanii without bacteria were used as a control. The number of $F$. novicida at each time point was determined by plating serial dilutions on BCYE agar plates. Amoeba cells were counted using light microscopy. Experiments were performed in triplicate and repeated three times. Student $t$-test, ${ }^{*} p<0.05$ was accepted as significantly different from the control sample.

used in this study. In both water samples, we observed very similar relationships between bacteria and amoebae. In both tested coculture models with amoebae, $F$. novicida showed enhanced survival compared to water samples without amoebae (Figures 3(a) and 3(b)). Within the coculture, bacterial counts were slowly decreasing from the initial $10^{7} \mathrm{CFU} / \mathrm{ml}$, and the bacterial numbers were constantly around 1-fold higher in comparison to samples without amoebae, where the numbers of $F$. novicida declined more progressively (Student $t$-test, $p<0.05$ ) (Figures 3(a) and 3(b)). Moreover, in the coculture models, F. novicida survived for 30 days, while in the control samples without amoeba, the bacterium was not detectable after 25 days of observation. Furthermore, the number of A. castellanii was also followed every 5 days. In both coculture models, the amoebal count was decreased from $10^{6} \mathrm{CFU} / \mathrm{ml}$, and after 20 days of incubation, we were not able to detect amoeba in the water samples. The counts of amoebae were constantly around 0.5 -fold higher in a control water sample without bacteria (Student $t$-test, $p<0.05$ ) (Figures 3(c) and 3(d)).

In parallel, the morphology of bacteria and amoebae was followed by TEM and light microscopy, respectively. In the coculture experiment with the presence of amoebae, $90 \%$ of the bacteria were roundly shaped, showing well-preserved cell structures with a smooth and intact cell wall (Student $t$-test, $p<0.05$ ) (Figures $4(\mathrm{a})$ and $4(\mathrm{~b})$ ). In contrast, multiple morphological changes of $F$. novicida were observed after incubation of bacteria in the control water samples 1 and 2 without the addition of amoebae (Figures 4(a) and 4(b)). Around $80 \%$ of bacteria showed a bacillar shape with highly undefined cell wall. Disorganized cytoplasm separated from the cell wall, with multiple clumping, was noticed in $70 \%$ of bacteria cultivated without amoebae (Student $t$-test, $p<0.05$ ) (Figures 4(a) and 4(b)).

The morphology of amoeba was also followed during 20 days of incubation. During the first 15 days of coculture, in all tested water samples, more than $60 \%$ of amoebae were present in a trophozoite form (Student $t$-test, $p>0.05$ ) (Figures 4(c) and 4(d)). However, after 20 days, we observed that within coculture models with bacteria, amoebae were in a resistant form termed cysts (68\% in water sample 1 and $64 \%$ in water sample 2), while in a control sample without bacteria, the majority of amoebae were still in a vegetative form of trophozoites, and significantly lower percent of amoebae were forming cysts (35\% in water sample 1 and $33 \%$ in water sample 2) (Student $t$-test, $p<0.05$ ) (Figures $4(\mathrm{c})$ and 


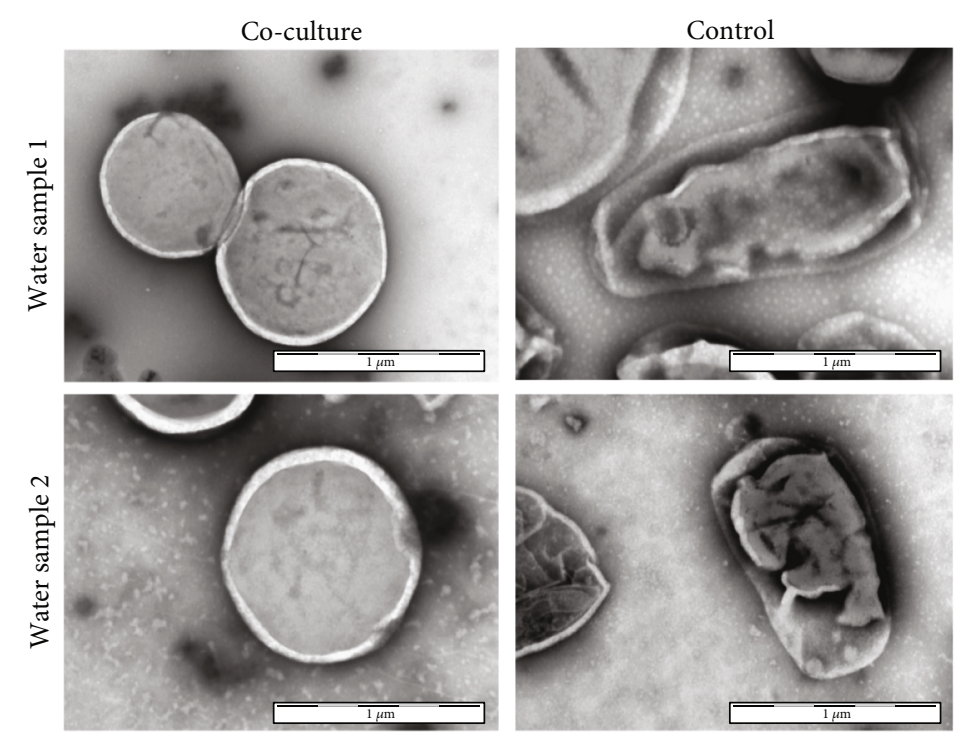

(a)

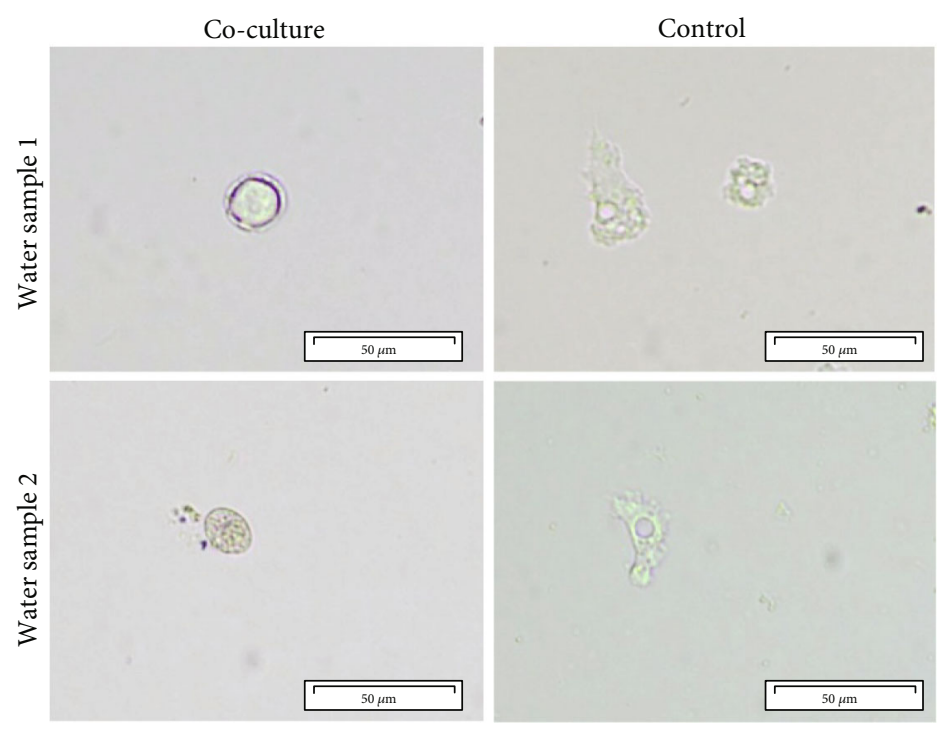

(c)
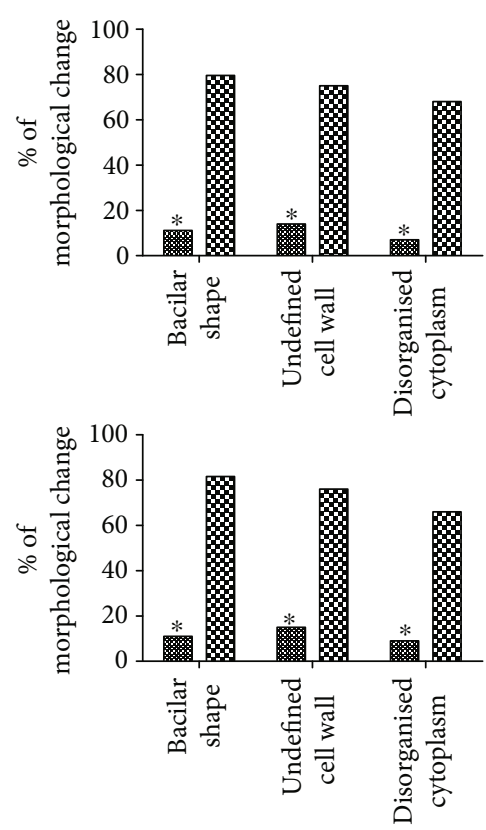

\& Co-culture

Fn control

(b)

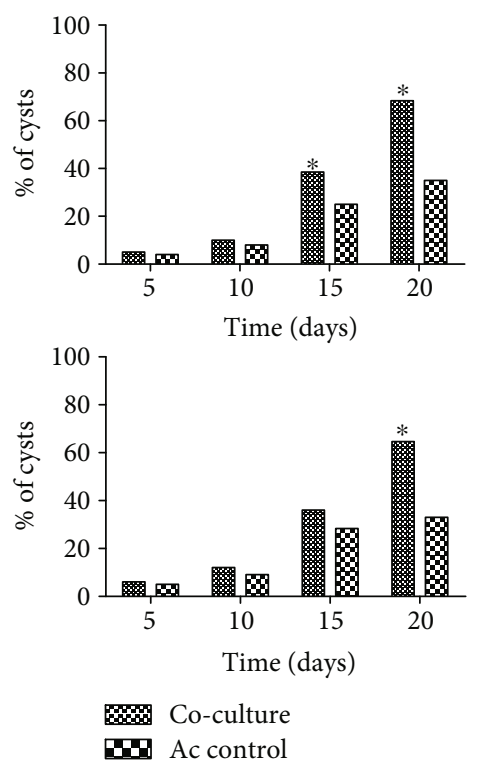

(d)

FIGURE 4: Morphology of F. novicida (a, b) and A. castellanii (c, d) was followed during the coincubation. (a) TEM analysis was performed to evaluate the morphology and structure of bacteria. Bacteria were negatively stained using $2 \%$ phosphotungstic acid. Representative images were acquired using a JEOL transmission electron microscope. Ten fields for each sample were randomly photographed. (b) By electron microscopy, we observed and described the morphology of bacteria, including their size, shape, and density. (c) The morphology of $A$. castellanii cells was observed using light microscopy. Representative images were acquired using an Olympus light microscope. Ten fields for each sample were randomly photographed. (d) By light microscopy, we observed and described the morphology of the amoebae including the percentage of amoeba cells present in a form of cysts. All experiments were performed in triplicate and repeated three times. Student $t$-test, ${ }^{*} p<0.05$ were accepted as significantly different from the control sample.

4(d)). These results are in consistence with the amoebal counts which showed that the presence of $F$. novicida in water is not beneficial for A. castellanii.
Our results are consistent with a previous study by El-Etr et al. showing that the virulent type A strain of F. tularensis is able to block lysosomal fusion in $A$. castellanii and survives in 


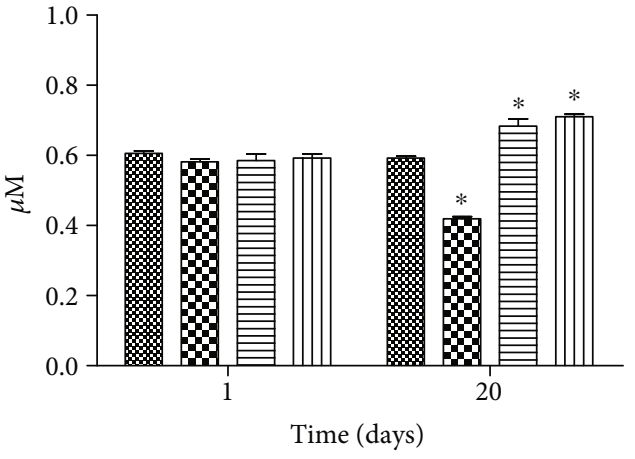

(a)

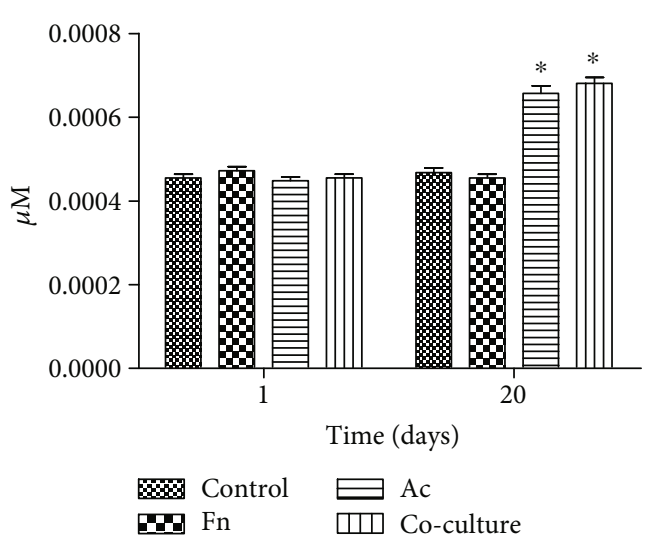

(c)

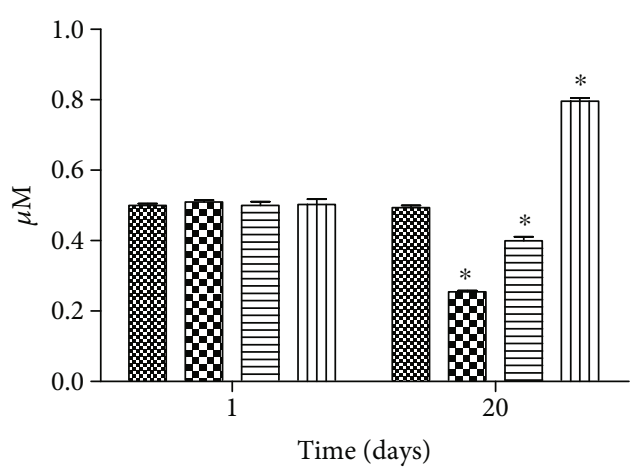

(b)

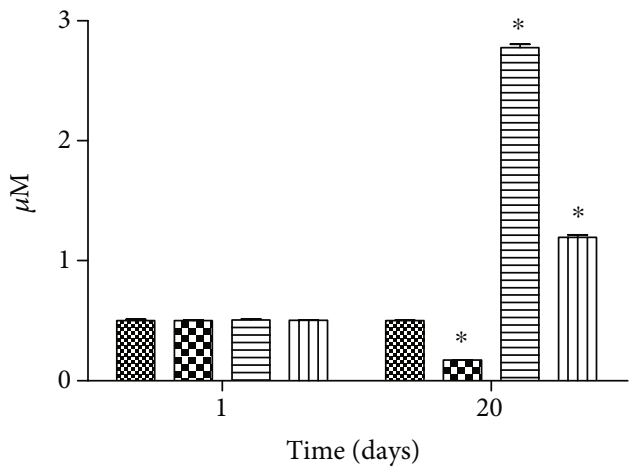

(d)

FiguRE 5: Determination of the concentration of manganese and zinc in water samples $1(\mathrm{a}, \mathrm{b})$ as well as in water sample 2 (c, d) after a coincubation. Before inoculation of the bacteria and/or amoeba, the initial concentrations of transition metals $\mathrm{Zn}$ and Mn were determined in all water samples using an atomic spectrometer (AAS, Perkin Elmer Analyst 200, SAD 2003). Analyses were performed according to the standards accepted by the Croatian Standards Institute. Water samples without addition of metal ions were used as a control. All experiments were performed in triplicate and repeated three times. Student $t$-test, ${ }^{*} p<0.05$ was accepted as significantly different from control samples without addition of bacteria.

A. castellanii cysts for at least 3-week postinfection. Moreover, they showed that the induction of rapid amoeba encystment is essential for the survival of F. tularensis [34]. We can assume that once inside the amoeba, the bacteria somehow trigger the encystation process which enables nutrient acquisition and protection from environmental conditions.

3.4. Consumption of Metal Ions during the Coculture. The concentrations of metal ions in the water samples were determined before and 20 days after the inoculation of bacteria and/or amoebae (Figure 5).

The initial concentration of manganese in control water sample 1 was $0.6 \mu \mathrm{M}$ as well as at day 20 (Figure 5(a)). In contrast, at 20 days after inoculation of bacteria, the concentration of $\mathrm{Mn}$ declined to $0.43 \mu \mathrm{M}$ (Student $t$-test, $p<0.05$ ), indicating the consumption of this metal ion by the bacterium. Surprisingly, the concentrations of Mn ions were even higher after 20 days of coculture of bacteria and amoeba $(0.72 \mu \mathrm{M})$ (Student $t$-test, $p<0.05)$. Similar results were obtained when only amoeba was inoculated in water samples $(0.68 \mu \mathrm{M})$ (Student $t$-test, $p<0.05)$ (Figure 5(a)). The initial concentration of $\mathrm{Zn}$ ions in water sample 1 was $0.5 \mu \mathrm{M}$. However, after inoculation of $F$. novicida, it declined to $0.25 \mu \mathrm{M}$
(Student $t$-test, $p<0.05)$. The presence of amoebae alone in water sample 1 resulted in the decreasing concentration of $\mathrm{Zn}$ in this water sample to $0.4 \mu \mathrm{M}$ (Student $t$-test, $p<0.05$ ) (Figure 5(b)). Finally, after 20 days of bacterium and amoeba coculture, we detected a significantly elevated $\mathrm{Zn}$ concentration of $0.8 \mu \mathrm{M}$ (Student $t$-test, $p<0.05$ ) (Figure 5(b)).

In water sample 2 , the initial concentrations of manganese were extremely low $(0.0005 \mu \mathrm{M})$ and did not change during a 20-day incubation of $F$. novicida (Student $t$-test, $p<0.05$ ) (Figure 5(c)). Interestingly, we observed significantly elevated levels of $\mathrm{Mn}$ ions after 20 days of coculture of bacteria with amoeba $(0.0007 \mu \mathrm{M})$ (Student $t$-test, $p<0.05)$ or amoeba alone $(0.00069 \mu \mathrm{M})$ (Student $t$-test, $p<0.05$ ) (Figure 5(c)). The initial concentration of $\mathrm{Zn}$ ions in water sample 2 was $0.5 \mu \mathrm{M}$ and declined to $0.17 \mu \mathrm{M}$ in a sample containing just $F$. novicida (Student $t$-test, $p<0.05$ ) (Figure 5(d)). Interestingly, in water sample 2, with amoeba, the concentration of $\mathrm{Zn}$ increased to $2.8 \mu \mathrm{M}$ after 20 days (Student $t$-test, $p<0.05$ ) (Figure $5(\mathrm{~d})$ ). After 20 days of bacterium and amoeba coculture, the concentration of $\mathrm{Zn}$ ions was also elevated in comparison to a control water sample without bacteria and/or amoeba $(1.2 \mu \mathrm{M})$ (Student $t$-test, $p<0.05)$ (Figure 5(d)). 
Consistent with the previously described results (Figures 2 and 1), we can conclude that $F$. novicida utilizes $\mathrm{Mn}$ and $\mathrm{Zn}$ ions within water sample 1 , as well as $\mathrm{Zn}$ ions in water sample 2 . We can conclude that $F$. novicida utilizes transition metals $\mathrm{Mn}$ and $\mathrm{Zn}$ for survival within water. Interestingly, within both coculture water samples, as well as in water samples containing just $A$. castellanii, we detected elevated concentrations of metal ions $\mathrm{Mn}$ and $\mathrm{Zn}$ after the incubation period of 20 days.

Also, in macrophages, amoebae develop complex mechanisms to regulate the import, export, and storage of transition metals and they are known to accumulate metals within intracellular organelles $[22,35]$. It has also been reported that M. tuberculosis infection triggers the accumulation of $\mathrm{Zn}$ within the macrophage phagosomes [36]. It might be possible that at certain conditions, or after cell death, these metal ions are released back to water. This could explain the elevated concentrations of $\mathrm{Mn}$ and $\mathrm{Zn}$ within the water samples with the addition of A. castellanii in a period of 20 days after inoculation, as well as the enhanced bacterial number and viability of $F$. novicida.

It has been shown that calcium, magnesium, and polyvalent metals play an important role in the formation of biofilms within the water environment [37]. Removal of calcium and magnesium metal ions from water created an environment that inhibits biofilm formation [37-39]. Within a biofilm matrix, a variety of additional microorganisms take up residence, including different bacteria and protozoa [40]. This becomes a good hunting area for phagocytic amoeba species which are able to engulf bacteria. Inside amoeba, Francisella is able to replicate and persist for a long period of time. One may conclude that transition metals support the persistence of amoeba within the water environment and thereby are a contributing factor for the growth of intracellular bacteria, such as Francisella.

\section{Conclusions}

Based on our results we can conclude that transition metals $\mathrm{Mn}$ and $\mathrm{Zn}$ are required for survival and growth of F. novicida in the water environment. In addition, high levels of $\mathrm{Zn}$ showed to be toxic for Francisella, while high concentrations of $\mathrm{Mn}$ do not have a negative effect on a survival of this bacterium. These findings suggest that for metabolic function, Francisella needs an exact concentration of $\mathrm{Zn}$ ions, while being more tolerant for $\mathrm{Mn}$ ions in the environment. Further, results from this study suggest that the presence of amoebae in natural waters enhances survival of $F$. novicida, while the presence of bacteria in water is not beneficial for amoeba.

\section{Data Availability}

The data used to support the findings of this study are included within the article.

\section{Disclosure}

We certify that the submission is an original work and is not under review by any other publication.

\section{Conflicts of Interest}

The authors have no conflicts of interest to declare.

\section{Authors' Contributions}

All coauthors have seen and agree to the contents of the manuscript.

\section{Acknowledgments}

We thank Majda Meden for supplying us with water from "Ponikve" on the island of Krk. This research was funded by University of Rijeka (Project Nos. uniri-biomed-128 and uniri-biomed-146) and Croatian Science Foundation's funding (Project No. HRZZ-IP-2016-06-9003).

\section{References}

[1] A. Sjödin, K. Svensson, C. Öhrman et al., "Genome characterisation of the genus Francisella reveals insight into similar evolutionary paths in pathogens of mammals and fish," $B M C$ Genomics, vol. 13, no. 1, p. 268, 2012.

[2] A. Hennebique, S. Boisset, and M. Maurin, "Tularemia as a waterborne disease: a review," Emerging Microbes \& Infections, vol. 8, no. 1, pp. 1027-1042, 2019.

[3] A. Vallesi, A. Sjödin, D. Petrelli et al., "A new species of the gamma-Proteobacterium Francisella, F. adeliensis sp. nov., endocytobiont in an Antarctic marine ciliate and potential evolutionary forerunner of pathogenic species," Microbial Ecology, vol. 77, pp. 587-596, 2019.

[4] J. J. Luque-Larena, F. Mougeot, B. Arroyo et al., "Irruptive mammal host populations shape tularemia epidemiology," PLoS Pathogens, vol. 13, no. 11, article e1006622, 2017.

[5] A. Sjostedt, "Tularemia: history, epidemiology, pathogen physiology, and clinical manifestations," Annals of the New York Academy of Sciences, vol. 1105, no. 1, pp. 1-29, 2007.

[6] I. Janse, R. Q. J. van der Plaats, A. M. de Roda Husman, and M. W. J. van Passel, "Environmental surveillance of zoonotic Francisella tularensis in the Netherlands," Frontiers in Cellular and Infection Microbiology, vol. 8, p. 140, 2018.

[7] Z. L. Berrada and S. R. Telford, "Survival of Francisella tularensis type A in brackish-water," Archives of Microbiology, vol. 193, no. 3, pp. 223-226, 2011.

[8] E. Denet, B. Coupat-Goutaland, S. Nazaret, M. Pelandakis, and S. Favre-Bonte, "Diversity of free-living amoebae in soils and their associated human opportunistic bacteria," Parasitology Research, vol. 116, no. 11, pp. 3151-3162, 2017.

[9] C. Balczun and P. L. Scheid, "Free-living amoebae as hosts for and vectors of intracellular microorganisms with public health significance," Viruses, vol. 9, no. 4, p. 65, 2017.

[10] I. Kelava, V. Marecic, P. Fucak et al., "Optimisation of external factors for the growth of Francisella novicida within Dictyostelium discoideum," BioMed Research International, vol. 2020, Article ID 6826983, 7 pages, 2020.

[11] E. O. Lampe, Y. Brenz, L. Herrmann et al., "Dissection of Francisella-host cell interactions in Dictyostelium discoideum," Applied and Environmental Microbiology, vol. 82, no. 5, pp. 1586-1598, 2015. 
[12] M. Santic, M. Ozanic, V. Semic, G. Pavokovic, V. Mrvcic, and Y. A. Kwaik, "Intra-vacuolar proliferation of $F$. novicida within H. vermiformis," Frontiers in Microbiology, vol. 2, p. 78, 2011.

[13] S. R. Telford and H. K. Goethert, "Ecology ofFrancisella tularensis," Annual Review of Entomology, vol. 65, no. 1, pp. 351372, 2020.

[14] J. Thelaus, A. Andersson, P. Mathisen, A. L. Forslund, L. Noppa, and M. Forsman, "Influence of nutrient status and grazing pressure on the fate of Francisella tularensis in lake water," FEMS Microbiology Ecology, vol. 67, no. 1, pp. 69-80, 2009.

[15] M. Forsman, E. W. Henningson, E. Larsson, T. Johansson, and G. Sandstrom, "Francisella tularensis does not manifest virulence in viable but non-culturable state," FEMS Microbiology Ecology, vol. 31, no. 3, pp. 217-224, 2000.

[16] C. Barisch, V. Kalinina, L. H. Lefrancois, J. Appiah, A. T. Lopez-Jimenez, and T. Soldati, "Localization of all four ZnT zinc transporters inDictyosteliumand impact of ZntA and ZntB knockout on bacteria killing," Journal of Cell Science, vol. 131, no. 23, p. jcs222000, 2018.

[17] C. A. Lopez and E. P. Skaar, "The impact of dietary transition metals on host-bacterial interactions," Cell Host \& Microbe, vol. 23, no. 6, pp. 737-748, 2018.

[18] J. A. Acosta, B. Jansen, K. Kalbitz, A. Faz, and S. MartinezMartinez, "Salinity increases mobility of heavy metals in soils," Chemosphere, vol. 85, no. 8, pp. 1318-1324, 2011.

[19] N. M. Perez and G. Ramakrishnan, "The reduced genome of the Francisella tularensis live vaccine strain (LVS) encodes two iron acquisition systems essential for optimal growth and virulence," PLoS One, vol. 9, no. 4, article e93558, 2014.

[20] G. B. Moreau, A. Qin, and B. J. Mann, "Zinc Acquisition mechanisms differ between environmental and virulent Francisella species," Journal of Bacteriology, vol. 200, no. 4, 2018.

[21] M. C. Abrantes, J. Kok, and M. F. Lopes, "EfaR is a major regulator of Enterococcus faecalis manganese transporters and influences processes involved in host colonization and infection," Infection and Immunity, vol. 81, no. 3, pp. 935-944, 2013.

[22] G. Weiss and P. L. Carver, "Role of divalent metals in infectious disease susceptibility and outcome," Clinical Microbiology and Infection, vol. 24, no. 1, pp. 16-23, 2018.

[23] G. Porcheron, A. Garenaux, J. Proulx, M. Sabri, and C. M. Dozois, "Iron, copper, zinc, and manganese transport and regulation in pathogenic Enterobacteria: correlations between strains, site of infection and the relative importance of the different metal transport systems for virulence," Frontiers in Cellular and Infection Microbiology, vol. 3, p. 90, 2013.

[24] M. R. Gonzalez, V. Ducret, S. Leoni, and K. Perron, "Pseudomonas aeruginosa zinc homeostasis: key issues for an opportunistic pathogen," BBA Gene Regulatory Mechanisms, vol. 1862, no. 7, pp. 722-733, 2019.

[25] S. C. Andrews, A. K. Robinson, and F. Rodriguez-Quinones, "Bacterial iron homeostasis," FEMS Microbiology Reviews, vol. 27, no. 2-3, pp. 215-237, 2003.

[26] O. Kolaj-Robin, D. Russell, K. A. Hayes, J. T. Pembroke, and T. Soulimane, "Cation diffusion facilitator family: structure and function," FEBS Letters, vol. 589, no. 12, pp. 1283-1295, 2015.

[27] C. Ratledge and L. G. Dover, "Iron metabolism in pathogenic bacteria," Annual Review of Microbiology, vol. 54, no. 1, pp. 881-941, 2000.
[28] J. A. Garza-Cervantes, A. Chávez-Reyes, E. C. Castillo et al., "Synergistic antimicrobial effects of silver/transition-metal combinatorial treatments," Scientific Reports, vol. 7, no. 1, p. 903, 2017.

[29] G. Greub and D. Raoult, "Microorganisms resistant to freeliving amoebae," Clinical Microbiology Reviews, vol. 17, no. 2, pp. 413-433, 2004.

[30] P. Scheid, "Relevance of free-living amoebae as hosts for phylogenetically diverse microorganisms," Parasitology Research, vol. 113, no. 7, pp. 2407-2414, 2014.

[31] V. Thomas, G. McDonnell, S. P. Denyer, and J. Y. Maillard, "Free-living amoebae and their intracellular pathogenic microorganisms: risks for water quality," FEMS Microbiology Reviews, vol. 34, no. 3, pp. 231-259, 2010.

[32] J. D. Cirillo, S. L. Cirillo, L. Yan, L. E. Bermudez, S. Falkow, and L. S. Tompkins, "Intracellular growth in Acanthamoeba castellanii affects monocyte entry mechanisms and enhances virulence of Legionella pneumophila," Infection and Immunity, vol. 67 , no. 9, pp. 4427-4434, 1999.

[33] M. Ozanic, I. Gobin, M. Brezovec et al., "F. novicida-infected A. castellanii does not enhance bacterial virulence in mice," Frontiers in Cellular and Infection Microbiology, vol. 6, p. 56, 2016.

[34] S. H. el-Etr, J. J. Margolis, D. Monack et al., "Francisella tularensis type A strains cause the rapid encystment of Acanthamoeba castellanii and survive in amoebal cysts for three weeks postinfection," Applied and Environmental Microbiology, vol. 75, no. 23, pp. 7488-7500, 2009.

[35] X. L. Hao, F. L. Lüthje, Y. Qin et al., "Survival in amoeba-a major selection pressure on the presence of bacterial copper and zinc resistance determinants? Identification of a "copper pathogenicity island"," European Journal of Applied Microbiology and Biotechnology, vol. 99, no. 14, pp. 5817-5824, 2015.

[36] H. Botella, P. Peyron, F. Levillain et al., "Mycobacterial p(1)type ATPases mediate resistance to zinc poisoning in human macrophages," Cell Host \& Microbe, vol. 10, no. 3, pp. 248259, 2011.

[37] L. Brouse, R. Brouse, and D. Brouse, "Natural pathogen control chemistry to replace toxic treatment of microbes and biofilm in cooling towers," Pathogens, vol. 6, no. 2, p. 14, 2017.

[38] R. M. Donlan, "Biofilms: microbial life on surfaces," Emerging Infectious Diseases, vol. 8, no. 9, pp. 881-890, 2002.

[39] M. A. Patrauchan, S. Sarkisova, K. Sauer, and M. J. Franklin, "Calcium influences cellular and extracellular product formation during biofilm-associated growth of a marine Pseudoalteromonas sp," Microbiology, vol. 151, no. 9, pp. 2885-2897, 2005.

[40] A. Abu Khweek and A. O. Amer, "Factors mediating environmental biofilm formation by legionella pneumophila," Frontiers in Cellular and Infection Microbiology, vol. 8, p. 38, 2018. 